\title{
A Mixed Methods Approach of End-of-Life Care, Social Rites, and Bereavement Outcomes: A Transnational Perspective
}

Cyrille Kossigan Kokou-Kpolou ${ }^{1,2}$ (D)

Charlemagne S. Moukouta ${ }^{1} \cdot$ Livia Sani $^{2}$.

Sara-Emilie McIntee ${ }^{3}$. Jude Mary Cénat $^{3}$ (iD .

Atiyihwè Awesso ${ }^{4} \cdot$ Marie-Frédérique Bacqué ${ }^{2}$

\begin{abstract}
The current article focused on examining the potential benefits of the End-of-Life (EoL) informal caregiving, communication, and ritualistic behaviors in adaptation to the conjugal bereavement across two different cultural-background contexts: France and Togo, West Africa. The investigation adopted a transnational approach including a total of 235 bereaved spouses. Despite the variation in the length of time since death, no significant difference was found between the Togolese and French bereaved with respect to the level of complicated grief symptoms. However, the Togolese bereaved perceived a significant postloss growth, fostered by EoL communication with the dying and the performance of ritualistic behaviors. In the French sample, bereaved individuals who had experienced more intimate communication with their dying spouse reported a high level of postloss growth. Moreover, findings showed that EoL caregiving without ritualistic support or communication is associated with poor postbereavement outcomes. These findings suggest a clinical need to promote informal caregiving to the dying, communication with the dying, and ritualistic support during the process of dying as entangled components of EoL care.
\end{abstract}

Résumé Dans cet article, nous avons examiné le potentiel effet positif de l'assistance au conjoint en fin de vie, de la communication avec lui et des actes rituels sur

\& Cyrille Kossigan Kokou-Kpolou kkkcyrille@yahoo.fr

Department of Psychology, University of Picardy Jules Verne, Amiens, France

Laboratoire Subjectivité, Lien Social et Modernité, University of Strasbourg, Strasbourg, France

3 Vulnerability, Trauma, Resilience and Culture Research Laboratory, University of Ottawa, Ottawa, Canada

4 Department of Anthropology, University of Lomé, Lomé, Togo 
le processus d'adaptation à la perte. Adoptant une approche transculturelle comparative, l'étude a été menée en France et au Togo (Afrique de l'ouest), deux contextes culturels differents dans leur approche du mourir, à la mort et au deuil. Les deux échantillons ont inclu au total 235 conjoints endeuillés. Bien que les deux échantillons ne soient pas homognènes pour la période du deuil, aucune différence significative n'a été constatée quant au niveau des symptômes du deuil compliqué. Cependant, les endeuillés Togolais ont plus rapporté une croissance postdeuil perçue surtout lorsque le défunt meurt âgé. Cette croissance postdeuil est également favorisée par la communication en fin de vie avec le mourant et l'accomplissement des actes rituels en soutien à la phase d'agonie. Dans l'échantillon français, la croissance postdeuil est plus vécue par les endeuillés qui avaient eu des communications plus intimes avec leur conjoint mourant. Nos résultats ont clairement montré que l'assistance au mourant sans un soutien rituel ou sans communication avec lui constituait un facteur de risque associé à un processus de deuil difficile. Ces résultats suggèrent, sur le plan clinique, de promouvoir la communication avec le mourant, les actes rituels symboliques dans l'accompagnement de la fin de vie et en particulier dans l'assistance des proches au mourant.

Keywords Spouse bereavement ' End-of-life care ' Rituals ' Complicated grief Postloss growth

Mots-clés Deuil du conjoint · Soins en fin de vie · Rituels · Deuil compliqué Croissance postdeuil

\section{Introduction}

Following the death of a significant person, most bereaved individuals go through a period of acute distress where the intensity of grief reactions recedes as time goes by. Evidence also suggests that some bereavers experience positive transformations of their lives following the loss. Grieving adaptatively requires resources at individual and social levels. The lack or inadequacy of mental and social resources could lead to the development of "persistent complex bereavement disorder" (American Psychiatric Association 2013) or "prolonged grief disorder"(World Health Organization [WHO] 2019), a persistent and pathological grief reaction also known as "complicated grief disorder" (see Shear et al. 2011). This clinical syndrome is a persistent and pervasive grief response characterized by longing for the deceased or persistent preoccupation with the deceased accompanied by intense emotional pain such as a difficulty in accepting the loss, feelings of sadness, and bitterness. It frequently entails a sense of emptiness and meaninglessness in regard to life and/or the future without the deceased and is associated with impaired daily psychosocial functioning (Prigerson et al. 1995; Shear et al. 2011; WHO 2019). It is commonly assumed that grief-related disorders are multidetermined, with some causal pathways depending on how the End of Life (EoL) and death are managed.

Previous studies have shown that postbereavement adjustment is influenced by factors related to the EoL, such as quality of caregiving and communication with the

\section{3}


dying loved one (Lövgren et al. 2018; Metzger and Matt 2008; Moon 2017; Schulz, Boerner and Hebert 2008). The current article focuses on examining the potential benefits of conjugal bereavement adapted EoL informal caregiving, communication, and ritualistic across two different cultural-background contexts: France and Togo (in West Africa). As stated by Walter (2012) and others, a comparative crossnational analysis in death studies are rare and untheorized. The current investigation resulted initially from the Ph.D. thesis project of the first author (CKK), involving dying and grief experiences in Togo and France, and subsequently from a research collaboration between researchers (co-authors) from both countries. This research project sought to provide a framework for understanding how both societies organize and ritualize the dying and grieving processes and their consequences on bereavement and health-related outcomes. It is rooted in the legacy of anthropological and psychodynamic research of a French pioneer thanatologist, LouisVincent Thomas, comparing many sub-Saharan African societies and the French society on systems of EoL, death, and mourning rituals (Thomas 1985). Here, specifically, this investigation sought to identify psychodynamic aspects of the EoL care that prepare for the mourning process and determine its outcomes while recognizing that EoL practices may vary widely in their form based on social contexts (Lee and Vaughan 2008; Thomas 1985). Using an implicitly cross-cultural comparative approach, the present study contributed to broadening our views and stances that often rely on western white culture grief models and to better understand the complexity of the mourning process and its outcomes in its social, cultural, and psychological aspects (Rosenblatt 2007; Walter 2012).

\section{Socioanthropological Perspective of Grief-Related Disorders}

From a socioanthropological point of view, the pathological forms of grief are the consequences of the desocialization and the deritualization of death and mourning (Gorer 1965; Thomas 1985). From this perspective, ritual acts contribute to alleviating the existential anguish of death. Indeed, the symbolic and therapeutic efficacy of rituals has been abundantly investigated. Imminent authors such as De M'Uzan (1977) and Thomas (1985) highlighted the great importance of EoL rites for containing and channeling the instinctual movements caused by dying, for giving meaning to gestures, and for promoting the mourning process of survivors.

Ritual can be defined as a sequence of acts, gestures, and words enacted in a given space during an important and critical period in the existence of a person or a group of people. The unfolding of a rite involves many actors who resort to symbolic gestures and sometimes material objects, with the aim of creating order in a life event or in a situation, and to give it a sublimated meaning (Sas and Coman 2016; Thomas 1985). Whether sacred, religious or secular in character, the ultimate purpose of the ritual is to give meaning and to provide a sense of security. By its structuring and calming power, it constitutes a support which goes beyond what is, even if only in the imagination of the individual, an existential crisis period. The abandonment of funeral rites deprives bereaved persons of symbolic landmarks of how to mourn. Precisely, "the deritualization of the dying process," wrote the sociologist Ziegler, "reduces postmodern man in the face of death by masking his 
agony and denying his dying status, by emptying death of all the existential meaning that it conveys" (Ziegler 2008). The passage towards death is increasingly experienced in the anonymity, solitude, and isolation of the hospital's technically sophisticated surroundings (Elias 1985; Thomas 1985). Last exchanges and interactions with the dying person (speeches, gestures...) are stifled and censured in silence, and sometimes proscribed. The mourning process before and after death is thus abridged, as it is considered a morbid condition that needs to be treated (Ariès 1974, 1981; Bacqué 2013). However, since the pioneering work of Glaser and Strauss $(1965,1968)$ and that of Kübler-Ross (1969, 1975), a considerable contribution has been made to changing perspectives and practices of dying and EoL care.

\section{EoL Care and Adaptation to Loss}

Based on existing literature, we propose that EoL care can be schematically conceptualized around three dimensions: EoL rituals, EoL caregiving, and EoL communication with the dying person. Across cultures, traditions, and religions, the EoL rituals comprises stimulation of all senses with the use of light (candles), perfumes (incense), anointing or massaging oil, sacraments or sacramentals, music, etc., as material or symbolic objects to ease the process of dying as well as the grieving process in the bereaved (Pace and Mobley 2016). Although, EoL rituals are perceived as important by some dying patients and their family members, there remains little empirical evidence of their positive effect on postbereament adjustment. We propose to empirically retest this assumption and to examine the impact of the EoL caregiving, and EoL communication on adapting to the loss.

Indeed, informal caregivers (surviving spouse, family members, relatives, and friends) often play a central role in the care of their dying loved one. A number of studies examined the potential benefits of EoL caregiving in postbereavement adjustment. The systematic review by Schulz, Boerner, and Hebert (2008; see also Boerner and Schulz 2009) led to three main conclusions on this issue. First, some studies found that caring for the dying did not facilitate the caregiver's adaptation to the loss. Rather, caregivers reported a greater level of postbereavement distress compared to non-caregivers. Schulz, Boerner, and Hebert (2008) attribute this result to the cumulative effects of stress generated by caregiving and death that may undermine the caregiver's adaptive strategies to loss. Second, other research findings support the opposite hypothesis, that the death marks the end of burdensome caregiving and of the anxiety and stress of the caregiver. Consequently, the grieving process seems less complicated among caregivers than among noncaregivers. Third, few studies have argued that informal care and assistance to the dying person enables caregivers to anticipate the loss and to cope better.

EoL communication between the dying and the surviving partner or family members decreases in frequency (e.g., McDonald et al. 2003). When it occurs, the communication is limited to factual information, such as the patient's treatment, their life expectancy, etc. Nevertheless, Keeley and Yingling (2007) found that caregivers who communicated with the dying person during their last days had less difficulty in making meaning in their loss and were able to reconstruct their identity

\section{3}


in positive way. The recent study by Yamaguchi, et al. (2017) also shed light on this topic. The study focused on Japanese bereaved people and showed that the bereaved family members who had had EoL discussions with the dying person reported very low levels of depressive symptoms as well as fewer complications related to the grieving process. These findings are somewhat congruent with some previous studies that found that more communication with the dying was related to more positive health outcomes in mourners (Beach 1995) and a higher degree of happiness with one's life following the death (Kramer 1997). This implies that the EoL communication could be helpful in terms of personal satisfaction and perception of positive psychosocial transformations with the grieving process.

\section{The Current Study and Objectives}

As shown, the dimensions of EoL care were documented separately. Furthermore, the available data related to the effects of EoL care on the grieving process are contrasted, especially with regard to EoL rituals and caregiving. The present investigation has integrated a splintered conceptualization by considering the EoL care as a meta-concept in which are embedded assistance or caregiving to the dying loved ones, communication with them and eventually ritualistic acts or behaviors performed to support the last passage of the dying. We particulary focused our attention on spouse bereavement-related outcomes, as the death of a spouse essentially requires the involvement of ritual support (Eisenbruch 1984a, b). Here, the bereavement-related outcomes involved the levels of complicated grief reactions and the postloss psychosocial transformations known as posttraumatic or postloss growth (Davis, Nolen-Hoeksema and Larson 1998; Edmonds and Hooker 1992; Hogan and Schmidt 2002; Tedeschi and Calhoun 2004). Indeed, adverse life events, such as the death of a significant person, can free up the sublimation capacities of the bereaved and be transmuted into a process of personal growth and maturation, characterized by positive changes in one's worldview or existential philosophy, an open-mindedness in one's relationships with others, and a greater positive appreciation of one's life.

The purpose of the present study was twofold. First, the study aimed to examine whether EoL informal caregiving to the dying, EoL communication focused on farewell speeches from the dying, and EoL ritualistic practices are associated with bereavement outcomes. The latter are predicted to be associated with lower levels of complicated grief reactions and higher levels of postloss growth indices, after controlling for personal factors (e.g., gender, age of the caregivers) and characteristics related to the bereavement (e.g., age of the deceased, type of death, and the time elapsed since the death). The second purpose was to describe the content of the farewell speeches of the dying reported by the caregivers and to identify the main ritualistic acts which constituted support during the agonizing period leading up to the death. Given the exploratory design of our investigation, we did not formulate specific hypotheses. 


\section{Methods}

\section{Brief Overview of Togolese Socio-cultural Context}

Togo is a multi-ethnic, French-speaking, Sub-Saharan African country where elderly people (from 65 years) represent $4 \%$ of the 7 million inhabitants. Widows and widowers make up 3\% of the general population. On a broader religious level, the traditional religion, deeply rooted in ancestorship, is the most popular religion (55\%), followed by Christianity, including all Christian denominations (35\%), and by Islam (10\%). However, religious syncretism as well as syncretism in healthcare (traditional, religious, and modern conventional care practices) is very common (Kokou-Kpolou et al. 2017). In health care settings, family caregivers often negotiate with health professionals to perform rites in favor of their dying loved one as a component of EoL care (Gysels et al. 2011; Mwangi-Powell, Powell and Harding 2013). In the collective representation, the dying process is a transition towards ancestorship, requiring social assistance and ritual support (Djassoa 1988; Thomas 1985). Greater importance is accorded to the last words of the dying person, assumed to be "sacred." When the dying person has not made a farewell speech, the family members often resort to geomancy practices in the disclosure of the ultimate wills of the deceased (Rivière 1982). In order words, the dying individuals have to make a final statement.

\section{Samples and Data Collection}

This is the first study on EoL care and grief including a sample from France, a Western Caucasian society, and one from a sub-Saharan African society where dying and grieving are embedded into important legacies of death and mourning rituals (Dassa et al. 2012; Kokou-Kpolou et al. 2016; Rivière 1982; Thomas 1985). The current article reports on two cross-sectional samples of 235 participants, including 162 Togolese (Study 1) and 73 French (Study 2) bereaved persons. Participants were all bereaved spouses with an average age of $55.3(\mathrm{SD}=10.56)$ years old. Table 1 presents the characteristics of the two samples. As expected, the contexts of the two countries are, in many aspects, not comparable in socioeconomic and cultural terms. Nevertheless, the data on several variables are homogeneous based on age of the bereaved spouses, age of the deceased, the length of conjugal life, etc.

Bereaved persons of both genders (male and female) who lost their spouse at least 6 months prior to the study were eligible to participate. In Togo, the study was conducted in three urban areas and seven rural locations. Participants were contacted through three widowers' associations. The survey was supervised by four clinical psychologists trained for the purpose of this study. During the initial phase, they presented the purpose of the study and the criteria for participation at the monthly meeting with the associations. Participants had to have a sufficient level of education to enable them to read and write. In the second phase, that is 2 weeks after the initial meeting, supervisors, in collaboration with those primarily responsible for

\section{3}


Table 1 Comparison of sociodemographic, loss-related characteristics, and scores on outcome measures between the two study samples

\begin{tabular}{|c|c|c|c|}
\hline Variables & $\begin{array}{l}\text { Togolese sample } \\
\text { n } \%\end{array}$ & $\begin{array}{l}\text { French sample } \\
\text { n } \%\end{array}$ & Group difference $\left(t / v^{2}\right)$ \\
\hline \multicolumn{4}{|l|}{ Sociodemographics } \\
\hline \multicolumn{4}{|l|}{ Gender } \\
\hline Female & $143(88.3)$ & $61(83.6)$ & 0.98 \\
\hline Male & $19(11.7)$ & $12(16.4)$ & \\
\hline Age, $M(\mathrm{SD})$ & $56.04(11.69)$ & $53.64(7.27)$ & 1.62 \\
\hline \multicolumn{4}{|l|}{ Education } \\
\hline University & $0(0.0)$ & $30(41.1)$ & na \\
\hline Secondary school & $50(30.9)$ & $43(58.9)$ & \\
\hline Primary school & $112(69.1)$ & $0(0.0)$ & \\
\hline \multicolumn{4}{|l|}{ Employment status } \\
\hline Employed & $82(50.6)$ & $43(58.9)$ & 1.39 \\
\hline Unemployed & $80(49.4)$ & $30(41.1)$ & \\
\hline \multicolumn{4}{|c|}{ Variables related to marital relationships (MR) } \\
\hline Duration of MR in year, M (SD) & $23.72(11.9)$ & $22.36(11.35)$ & 0.82 \\
\hline Satisfaction with MR, M (SD) & $4.18(0.94)$ & $4.48(0.65)$ & $-2.38 *$ \\
\hline \multicolumn{4}{|l|}{ Number of children } \\
\hline \multicolumn{4}{|l|}{ Bereavement-related characteristics } \\
\hline Age of deceased, M (SD) & $53.78(14.46)$ & $53.82(7.17)$ & 0.98 \\
\hline \multicolumn{4}{|l|}{ Cause of death } \\
\hline Brutal, violent death & $28(17.28)$ & $48(65.75)$ & $54.03 * * *$ \\
\hline Natural expected, sudden death & $124(82.72)$ & $25(34.25)$ & \\
\hline Time since loss in year, $M(\mathrm{SD})$ & $9.38(7.89)$ & $2.27(1.94)$ & $-7.58 * * *$ \\
\hline \multicolumn{4}{|l|}{ Outcomes } \\
\hline ICG-R & $34.43(\mathrm{SD}=12.03)$ & $36.74(\mathrm{SD}=11.31)$ & 0.157 \\
\hline PLG/PTGI & $34.35(\mathrm{SD}=6.69)$ & $34.36(\mathrm{SD}=8.07)$ & -0.10 \\
\hline SP-PLG & $0.33(\mathrm{SD}=2.65)$ & $-1.51(\mathrm{SD}=2.41)$ & $5.04 * * *$ \\
\hline
\end{tabular}

The sample differences in the age (of bereaved and deceased), duration of MR, satisfaction with MR, time since the loss, and scores on outcome variables were tested by $\mathrm{t}$ tests. Categorical variables including gender, employment status, and the cause of the death were examined by $v^{2}$ tests. Education was not tested given that 2 cell frequencies were equal to 0 , reflecting the large difference in level of education completed in both samples

MR marital relationship, M mean, SD standard deviation, ICG-R Inventory of Complicated Grief-revised, PLG/PTGI postloss growth as measured by the Posttraumatic growth inventory

$* \mathrm{p} \searrow 0.05$

$* * \mathrm{p} \backslash 0.01$

$* * * p \backslash 0.0001$ 
these associations, collected the completed questionnaires. Data collection took place from November 2015 to March 2016.

In France, we used two field sampling techniques. First, recruitment of participants took place through grieving groups on social networks. This technique appeared to be time efficient and less costly but had an important limitation: it restricted participation to Internet users only, thus limiting the number of elderly participants. Second, we approached the grieving groups of the Catholic churches of the city of Amiens, in the North of Paris, to conduct recruitment. Only bereavement registries from 2010 to 2016 were kept up to date, therefore we sent the questionnaire to widows/widowers who had lost their spouses within this period (on average 27.27 months after the loss) of time. To a certain extent, this second technique compensated for the limitations of the former. Altogether, the data collected in France covered the time period between April and November 2016.

\section{Ethical Considerations}

Prior to data collection, we obtained ethical approval from the Social Sciences Research Ethics Committees from University of Picardy Jules Verne (France) and University of Lomé (Togo). We then sent letters to the leaders of three widowers' associations in Togo and to the bereavement teams and administrators of the websites of the bereavement support groups in France explaining the purpose and relevance of the study. All participants voluntarily agreed to participate in the study and signed the informed consent form. Participants could withdraw their participation at any given time and if necessary, seek guidance from the referred individuals whose contact informations were given on the consent form.

\section{Assessments}

Demographics

Participants provided informations about their gender, age, educational level, socioprofessional status, religious affiliation, and residence area.

Marital Relationship and Variables Related to Death

We also collected data on marital relationship (duration of and satisfaction with marital relationship, number of children) and data on spouse's death (age of the deceased, circumstances of death, type of death, place of death, time elapsed since the loss).

\section{EoL Information}

EoL information was collected from a questionnaire consisting of six questions, four of which were closed, and two were open-ended. Participants provided information on whether they had assisted the dying spouse during the 2 weeks leading up to the death (yes/no). If yes, they were asked to estimate the amount of assistance provided

\section{3}


in terms of hours. However, Togolese participants in particular did not take interest in this question. They found it inconvenient to estimate this time as they were "day and night" with the dying person, suggesting that they were providing full-time care compared to their French counterparts who provided occasional care. The next question was whether the passage towards death had been ritualized (yes/no). If yes, participants described the rituals performed. Finally, they stated whether they had had discussions with the dying person during which the latter made a farewell speech. If so, they could, if they wished, give a summary of the words spoken by the dying person. We thus emphasized the farewell speech because, as pointed out by Keeley and Yingling (2007), it represents the last words of the dying, which have significant meaning for the surviving spouse and defuse the pathogenic process. For ethical reasons, participants were not obliged to report these words if they felt that they were intimate.

These questions allowed us to constitute six groups, a posteriori, based on the type of support given to the dying. The groups were as follows: group 1 (no caregiving ? no communication ? no ritual acts), group 2 (ritualistic acts ? no communication), group 3 (caregiving), group 4 (caregiving ? ritualistic acts), group 5 (caregiving ? communication), and Group 6 (caregiving ? communication? ritualistic acts).

\section{Complicated Grief Reactions}

The French version of the Inventory of Complicated Grief-Revised (ICG-R; $\mathrm{K}$ 'delant 2010) was used to measure grief reactions. This abbreviated version is comprised of 17 items and had already been validated in France (K'delant 2010), and then adapted in Togo (Kokou-Kpolou et al. 2016, 2017). Participants responded to each item on a Likert scale, from 0 to $4(0=$ almost never to $4=$ always $)$. One item measures the level of disruption of psychosocial functioning. In the present study, Cronbach's alpha was 0.88 in the Togolese sample and 0.92 in the French sample.

\section{Postloss Growth (PLG)}

The PLG was evaluated by the Posttraumatic Growth Inventory (PTGI) developped by Tedeschi and Calhoun (1996), a 21-item measure of positive changes that may be experienced in the aftermath of loss. Participants responded to each item on a scale graded from 0 (not at all) to 5 (totally) evaluating the occurrence of personal changes that had arisen pursuant to the loss. This instrument yields five dimensions: relating to others, new possibilities, personal strength, spiritual change, and appreciation of life. In the present study, only the total score (without the itemrelated religious practices due to the confusion between spirituality and religion practices in Togolese context) was considered. The Cronbach alpha was 0.77 in the Togolese sample and 0.86 in the French sample. 
We added to the PTGI a visual analog scale (VAS) to assess the overall perception of psychosocial change subsequent to the loss. The scale is rated from -5 to ? 5: the values of a negative perception range from -5 to -1 , a perception that was neither negative nor positive is rated as 0 , whilst the values of a positive perception range from ? 1 to ? 5 .

Data Analysis Plan

Analyses of quantitative data were performed using IBM SPSS 21 (SPSS Inc., Chicago, IL, USA). Basic descriptive analyses were carried out to describe the profile of participants according to sociodemographic data, characteristics of marital relationship, and characteristics of bereavement. Then, a Chi-square and Student's t tests weres used, as appropriate, to compare the two sample-based study variables (see Table 1). A bivariate correlation analysis was also tested between some continuous variables. Further, we performed a multivariate analysis of covariance (MANCOVA) to examine differences between EoL modalities and outcome variables after controlling for covariates (sociodemographic and bereavementrelated characteristics). The effect size was reported in terms of omega squared $\left(\mathrm{x}^{2}\right)$. A post hoc multiple-comparison analysis between groups was used. The Bonferroni method was applied to correct for risk inflation of the alpha.

Using a mixed methods approach, the qualitative data from open-ended questions were examined using a thematic content analysis (Bardin 2003). Data coding was done separately by two authors of this article. The encoded data were compared to reduce subjective biases in the analysis.

\section{Results}

Study 1: End-of-Life Care and Bereavement Outcomes in Togolese Bereaved Sample

Descriptive Analysis

Profile of Participants The mean age was $56.04(\mathrm{SD}=11.7)$ years old. With regard to education, $69.1 \%$ had achieved primary level and $30.9 \%$ secondary level (secondary or high school). In terms of occupational status, $50.6 \%$ were employed, compared to $49.4 \%$ who were unemployed or retired. As for religious affiliations, $59.3 \%$ were Catholics and Protestants, 9.3\% belonged to Pentecostal or charismatic obedience churches, whilst $31.5 \%$ were followers of the traditional religion (animism). Nearly $57 \%$ of participants lived in the countryside and $43.2 \%$ in an urban setting.

\section{3}


Bereavement-Related Characteristics The average age of the deceased was 53.8 $(\mathrm{SD}=14.5)$ years old. In $58.6 \%$, compared to $41.4 \%$ of the cases, death of the spouse was unexpected. Death predominantly, occurred following sudden or chronic illnesses $(80.2 \%) ; 54.3 \%$ of deaths were perceived as good deaths (natural deaths), and $45.7 \%$ were perceived as a bad deaths (violent deaths, particulary due to fatal accidents). Death occurred in the hospital in $51.2 \%$ of cases and at home in $46.3 \%$ of cases. The ritualitization of death was not determined by whether death occurred in the hospital or at home. The average duration of mourning was $9.38(\mathrm{SD}=7.89)$ years.

Marital Relationship and Ritualization of Death The satisfaction with the marital relationship was reported by $81.5 \%$ as being very good or good. The average duration of conjugal life was 23.7 years $(\mathrm{SD}=11.9)$. In regard to the ritualization of death, results indicated that $74.7 \%$ of participants attended the dying person personally before they died, with men $(100 \%)$ being more likely to do so than women $(71.3 \%)$. In $23.5 \%$ of cases, the final passage of the dying person was supported by rituals. A farewell speech was made by 1 out of 4 deceased $(73.2 \%$ of men vs. $26.8 \%$ of women).

\section{Correlation Analysis}

We found a significant association between total score on ICG-R and gender $(\mathrm{r}=-0.17, \mathrm{p} \backslash 0.05)$, suggesting that widows were less at risk for complicated grief (CG) symptoms than widowers. CG symptoms also negatively correlated with time since the death $(\mathrm{r}=-0.21, \mathrm{p} \backslash 0.01)$. No significant correlations were found between score on ICG-R and postloss growth or the self-percieved postloss growth. This indicates that postloss growth is a construct independent of that of CG symptoms.

\section{Multivariate Analysis}

Figure $1 \mathrm{~A}$ and $\mathrm{B}$ show that there were no significant differences between the EoL groups with regard to scores on ICG-R or personal growth after the loss. In both cases, neither the expectedness of the loss, nor the time since the loss influenced the outcome variables. As for the CG reactions, Groups 6 and 4 seemed to face with fewer complications than the other groups. This difference appears even more significant when we look at the effect of time since the loss; this could be attributed to the performance of rituals: when a ritual is associated with caregiving, it produces a beneficial effect on the bereavement process in such a way as to decrease the intensity of mourning of the spouse more quickly. Moreover, as shown in Fig. 1c, there was a significant association between the different groups and the perception of personal growth $\left(\mathrm{F}=2.41, \mathrm{p} \backslash 0.05, \mathrm{x}^{2}=0.75\right)$. Groups 6 and 5 , compared to Group 1, had a strong positive perception of their lives after the loss. This difference is explained by the effect of age of the dying person: the older the dying person was, 
Fig. 1 Differences between EoL care groups and outcome measures in Togolese sample. EoL End-of-Life. G1 $(\mathrm{n}=22$ $13.6 \%), \mathrm{G} 2(\mathrm{n}=20 ; 12.3 \%), \mathrm{G} 3$ $(\mathrm{n}=72 ; 44.4 \%), \mathrm{G} 4(\mathrm{n}=22$; $13.6 \%), \mathrm{G} 5(\mathrm{n}=19 ; 11.7 \%)$, and G6 ( $\mathrm{n}=7 ; 4.3 \%)$. Error bars denote $95 \%$ confidence intervals.

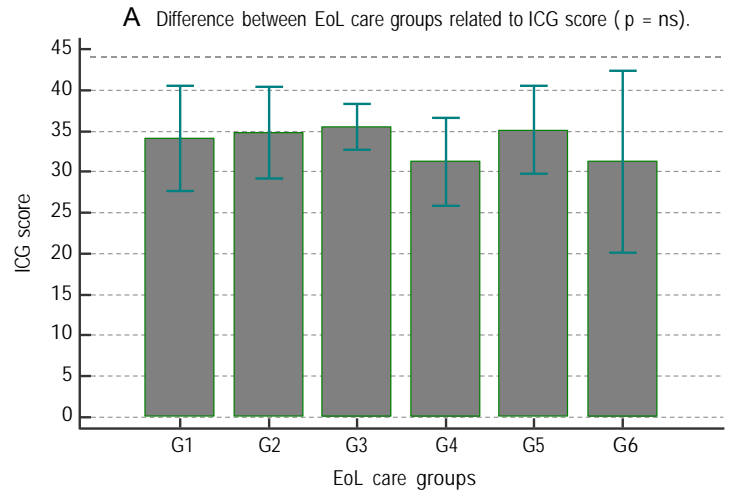

B Difference between EoL care groups related to PLG score $(p<0.10)$

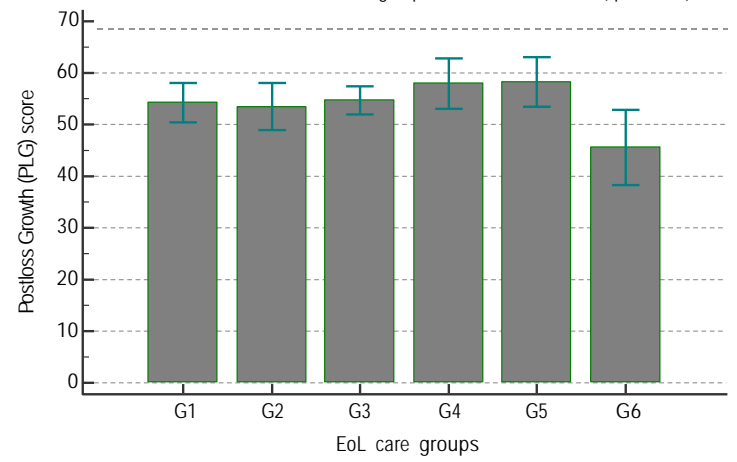

C Difference between EoL care groups related to SP-PLG score $(p<0.05)$

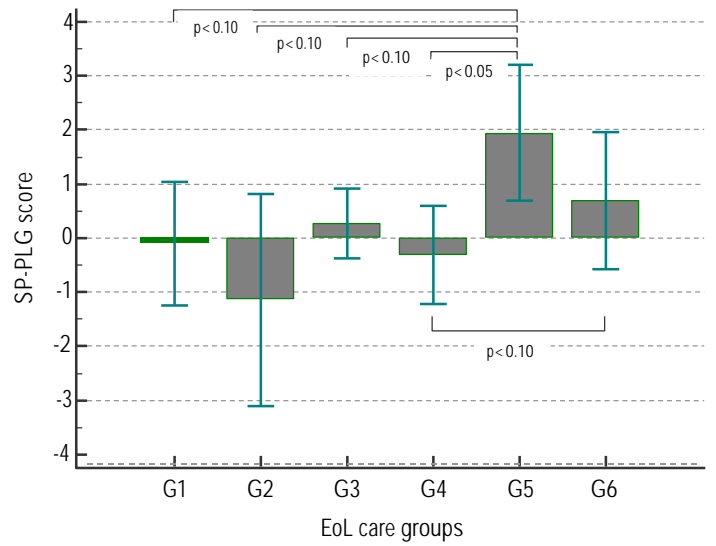

the more Groups 6 and 5 reported that they perceived positive transformations in their lives after the loss.

\section{3}


Three types of ritualistic support have been identified. In descending order, these include prayers to ancestors, the sacrament of the anointing of the sick, and nonsacramental prayers. Of the 41 participants who reported that the dying person made a farewell speech, 32 disclosed what had been said. In total, seven categories were retained using thematic analysis.

Theme 1: The acceptance of death: In this category, we noted that $25 \%$ of the dying reported a feeling of imminent death. They expressed it by emphasizing: "My death is imminent, the ancestors are calling me," "Now the time to leave has arrived," "My wife, I am leaving." Sometimes the separation was more painful: "Darling, I am going to leave you. How very sad I am!"

Theme 2: Recommendations for the education of children: This category was the most represented $(40.6 \%)$. The education of children appeared to be of concern for the dying: "Dry your tears and find the courage to take care of the children," "My husband, watch over our children," "Educate our children in the fear of God." The recommendation was sometimes specific: "[On many occasions he told me] take good care of our second daughter." Or, it may have been addressed to the whole audience: "My friends, watch over my children."

Theme 3: Transmission of values: Three values were at the heart of the farewell speeches of the dying. First, unity of the family: "My children, I leave you today. Stay together," "Let the whole family unite in order to live happily." Then, respect: "Have respect for everyone." Finally, work and success: "My children, I have not left you anything by way of material heritage. But learn well, succeed in your studies in order to become something tomorrow."

Theme 4: Guidelines or last wishes of the dying: In $25 \%$ of cases, the dying man formulated his "last will": "Give me a drink, then call another member of my family to witness this moment." "[On the eve of his death, he told me] to call the priest to pray for us as on the day of our marriage," "Take me back to the North, to my village home." The instructions to be followed after death were also expressed: "Tell the oldest son to organize a move for our own house," "He told me where the papers were for the widowhood allowance procedures."

Theme 5: Promise of support and protection beyond the death: Quite often the dying man reassured his spouse and his children by saying that he would continue to be a support and means of protection to them: "I will always be by your side," "I will think of you and our children," "[At a time when I was pregnant] Do not imagine I will leave you alone, I will always be there."

Theme 6: Words of consolation: The farewell speech was marked by words of consolation in $25 \%$ of the cases: "Dry your tears and find the courage to take care of the children," "My wife, I thank you for having been by my side during these moments of illness. Be strong," "During all our life together, I have remained faithful to you. God will keep you."

Theme 7: Revelation, forgiveness, and reconciliation: Finally, in the speech of a dying person, there was a confession associated with an exchange of forgiveness: "Darling, forgive my infidelity. Consider the child out of wedlock as yours...." 


\section{Partial Discussion}

These results suggest the importance to have another look at the grieving process. Indeed, bereaved spouses who reported less complicated grief reactions were not systematically those experiencing positive psychosocial changes in their lives after the death of their spouse. This result confirms what was highlighted by Currier et al. (2013), that postloss growth can occur independently of the intensity of grief reactions. In the present study, postloss growth was more commonly reported by caregivers who had had EoL communication with the dying person, marked by the person's farewell speech, or when this farewell speech was associated with the performance of ritualistic acts. Gamino, Sewell, and Easterling (2000) found that postloss growth is associated with attending to the dying, saying goodbye, and having a form of spirituality. In a very large proportion of cases, the dying person was attended to by their family and EoL rituals of passage were completed. The different themes of communication identified denote a socialization of the passage towards death and a network of solidarity created around the dying. The death process offers the dying person a social space for the transmission of values, and for the relatives, space for reflection on life and death.

Study 2: End-of-Life Care and Bereavement Outcomes in French Bereaved Sample

Descriptive Analysis

Profile of the Participants The mean age was $53.6(\mathrm{SD}=7.3)$ years old and was homogeneous for women $(\mathrm{M}=53.7 ; \mathrm{SD}=7.6)$ and men $(\mathrm{M}=53.50 ; \mathrm{SD}=5.5)$. Approximatively $59 \%$ of participants had a secondary education and $41.1 \%$ had achieved a higher education or university level education. Similarly, 59\% had a part-time or full-time professional occupation compared to $41 \%$ who were unemployed or retired. In terms of religious affiliation, $57.5 \%$ reported being Catholic and $42.5 \%$ had no religious affiliation.

Bereavement-Related Characteristics The average age of the deceased was 53.8 $(\mathrm{SD}=7.2)$ years old. The time span since the death was $2.27(\mathrm{SD}=1.94)$ years. Almost $66 \%$ of participants $(n=48)$ reported that their spouse died suddenly or under violent circumstances. The majority of deaths $(n=57 ; 75.3 \%)$ occurred in hospital or in a care facility; 12 deaths occurred at home, 2 in health services, 2 in prison, and 2 were unspecified.

Marital Relationship and Ritualisation of Death Approximatively, 92\% of participants reported they were satisfied with the martital relationship ("very good" or "good"). The average duration of marital relationships was 22.36 ( $\mathrm{SD}=11.35)$ years. Thirty-one participants $(\mathrm{n}=31,42.5 \%)$ were present with their spouses before they died. In $24.7 \%$ of the cases, the dying had been the subject of some sort

\section{3}


of ritual and $21.9 \%(n=16)$ of participants reported that the deceased gave a farewell speech.

\section{Correlation Analysis}

The summed scores on ICG-R are inversely correlated with postloss growth $(\mathrm{r}=-0.51, \mathrm{p} \backslash 0.001)$, self-perceived postloss growth $(\mathrm{r}=-0.55, \mathrm{p} \backslash 0.001)$, and time elapsed since the loss $(\mathrm{r}=-0.27, \mathrm{p} \backslash 0.05)$. This pattern of findings suggests that the process of postloss growth is effective and evaluated as positive while the intensity of grief reactions decrease as time goes by.

Multivariate Analysis

Figure 2A shows a slightly significant relationship between EoL groups and CG reactions $(\mathrm{F}=2.19, \mathrm{p}=0.09)$. The post hoc comparison analysis shows a significant difference between groups 5 and $3(\mathrm{p} \backslash 0.05)$. Grief symptoms in Group 5 are less complicated than in Group 3. When examining the effects of the age of the deceased spouse and the duration of mourning separately, this betweengroup difference (Group 5 and Group 3) was not significant, suggesting that the less severe grief reactions of the caregivers of Group 5 cannot be explained by the age of the deceased or the duration of mourning.

As depicted in Fig. 2B and $\mathrm{C}$, the results revealed a significant relationship between EoL groups and postloss growth $\left(F=3.71, p \backslash 0.01, x^{2}=0.88\right)$, as well as self-perceived postloss growth $\left(\mathrm{F}=3.31, \mathrm{p} \backslash 0.05, \mathrm{x}^{2}=0.73\right)$. Bereavers in Group 5 reported higher levels of postloss growth than those from other three groups. They were also more likely to report higher levels of self-perceived postloss growth than those in Groups 2 and 3.

Qualitative Analysis

Among the EoL ritual support practices, some of the surviving spouses reported having lit a candle at the bedside of the dying, while others recited a poem or prayers, one of which placed a rosary in the hands of the dying person. Some played to the dying persons one of their favorite songs. Following the examination of the contents of the 9 disclosed farewell speeches, four thematic axes were identified.

Theme 1: Expression and renewal of love: Four responses evoked an exchange of words of love, two of which reflected the idea of preserving the attachment of their bond beyond the imminent death: "I love you"; "Let her love me"; " I will always love you."

Theme 2: Struggle between despair and resignation: Two responses highlighted the dying person's final struggles with disease, including cancer. The weight of suffering ended by provoking despair and resignation in the face of death, now desired as a denouement: "[He wanted it to stop, because he was suffering too much.]" , "I fought for you but I want it to stop now" [this spouse died of cancer].

Theme 3: Regrets: In one case, the dying man expressed regrets, denoting a feeling of unfinished happiness. The dying man would have liked to fully enjoy the 
Fig. 2 Differences between EoL care groups and outcome measures in French sample. EoL End-of-Life. Depending on the combinations, there were no Group 6 (caregiving ? ritual acts ? communication) and Group 4 (caregiving ? ritual acts) in the French sample. The groups were constituted as follows: $\mathrm{G} 1(\mathrm{n}=21 ; 28.8 \%)$, G2 $(\mathrm{n}=26 ; 35.6 \%), \mathrm{G} 3(\mathrm{n}=13$; $17.8 \%)$, and $\mathrm{G} 5(\mathrm{n}=13 ; 17.8 \%)$. Error bars denote $95 \%$ confidence intervals.

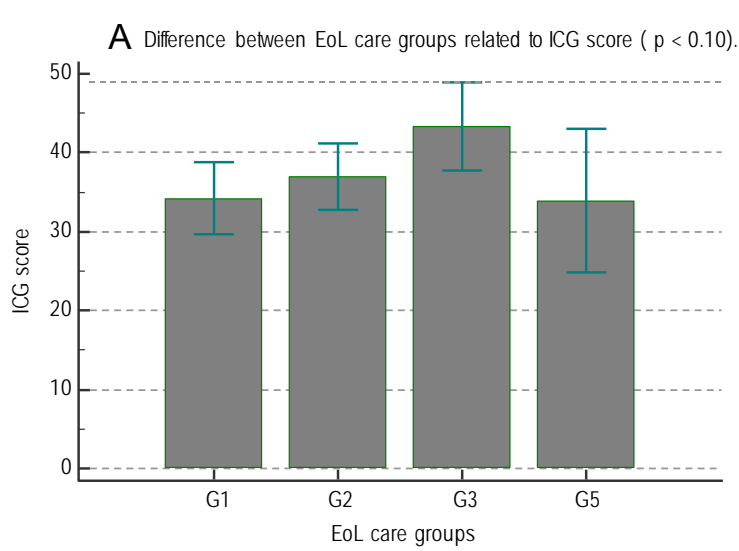

B Difference between EoL care groups related to PLG score $(p<0.01)$

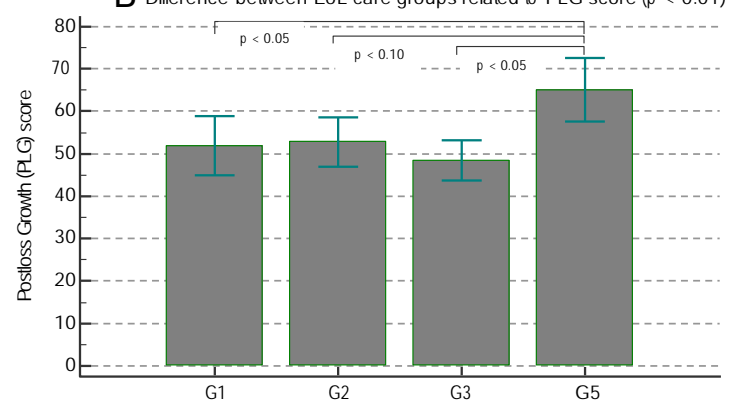

EoL care groups

C Difference between EoL care groups related to SP-PLCscore $(p<0.05)$

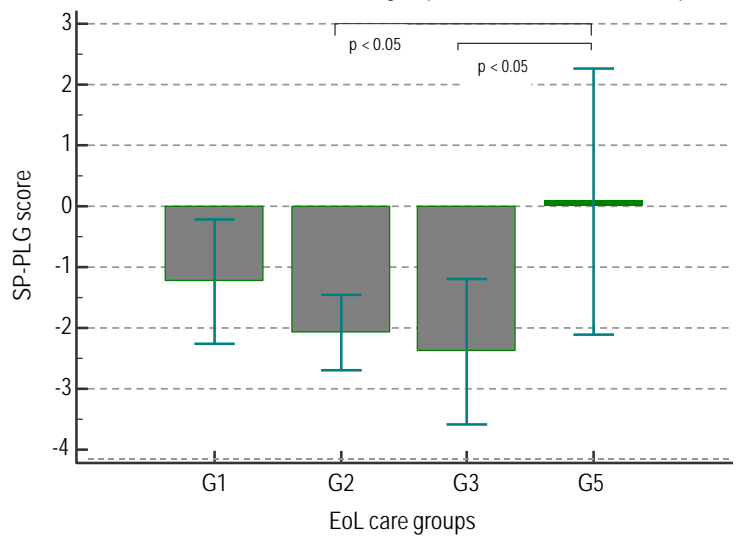

happiness of seeing his children, for whom he feels a great attachment, grow. "[It was his regret that he would not live to see the children grow up.]"

Theme 4: Advice and guidelines: Two occurrences related to advice and guidance given to the surviving spouse. In one case, it was a dying man who

\section{3}


exhorted his wife to be strong: "[He told me to] be strong." In the other case, it was a woman who encouraged her spouse to rebuild his life after her death: "[She also told me she wanted me to lead an active life after her death.]"

\section{Partial Discussion}

In the French context, complicated grief reactions and postloss growth are two inversely related phenomena. Painful grieving compromises the process of postloss. Hogan and Schmidt (2002) reported similar results with the bereaved parents of a child. In this study, it appears that caregiving associated with EoL communication with the dying has a positive effect on adaptation to the loss. With the effect of time, caregiving and EoL communication promote relief from the grief-related pain of bereavement and amplify postloss growth. This result is in line with that observed in the study by Yamaguchi et al. (2017), where bereaved family members who had EoL discussions reported less complications during the grieving process. In addition, our study found that spouses whose caregiving was not supported by ritualistic acts or associated with farewell communications reported severe grief reactions. This result seems to be oriented towards the hypothesis of attrition, formulated by Schulz, Boerner and Hebert (2008) and that of Boerner and Schulz (2009), which states that assistance to the dying person exhausts caregivers' resources and explains their level of distress and increased mourning complications compared to non-caregivers. This result is of great interest because it shows that caregiving without ritualistic support may render the caregiving spouse vulnerable to complicated grief symptoms.

\section{General Discussion}

In view of the first purpose of the present investigation, our findings provide an interesting twofold reading about postbereavement symptomatology. First, the mourning reactions and personal growth following the death are two concomitant processes among Togolese mourners. Complicated grief reactions did not systematically alter the perception of a better life following the loss. The two processes may interact and change simultaneously. This positive and dynamic perception of postloss is better explained by two factors: the age of the deceased and EoL caregiving associated with ritualistic support. These results relate to the ethnotheory of a "good death." The deceased had a "good death," if they died at an older age, peacefully, surrounded by their own. As Djassoa (1988) wrote about many Togolese communities, "assistance to an elderly dying person is an imperative duty, even a cultural injunction, the accomplishment of which is accompanied by a blessing." $\mathrm{He}$ explicitly wrote "if someone dies abandoned in the absence of his children, the children have to offer a sacrifice of reparation to avoid paying for it with their own life or health" (Djassoa 1988: 174). This conception, based on the principle of intergenerational solidarity, maintains a sense of duty with regard to the elderly and the dying, on the one hand, and the socialization of the passage towards death, on the other. The dying person is considered as someone in the process of 
ancestralization, with whom a connection based on respect and assistance brings rewards. The high proportion $(74.7 \%)$ of spouses who attended the dying until the last hours of their death suggests a certain level of importance attributed to the symbolic "benefits" of the EoL caregiving. In the French sample, caregiving spouses who experienced EoL communication with the dying (Group 5), reported relatively less intense grief reactions. The same group reported a more significant level of postloss growth than the other groups. In the Togolese sample, with a few exceptions, spouses whose caregiving was supported by ritualistic acts or associated with farewell speeches from the dying person, reported less complicated grief reactions. However, it was clearly established in both cultural contexts that EoL caregiving without ritualistic support (Group 3) was a risk factor associated with overwhelming postbereavement distress. While caregiving is undeniably an emotional and material support of great necessity, in the present study, it was even more important and vital when it was accompanied by ritualistic acts to reduce and give meaning to the anguish of the ultimate phase of life. These results suggest that EoL rituals may play the role of "creating meaning" and build a bridge between life and death (Van Gennep 1908/1960). Thus, through subtle rituals, the painful reality of loss is moved into the register of symbolism where it can become less difficult to mentalize and integrate (Bacqué 2013). Results also suggest that the positive impact EoL rituals of death, which are indispensable for humanizing, socializing, and giving meaning to the passage towards death, is amplified by the effect of the time elapsed since the death. This insightful result fosters the integration of the dimension of time into our understanding of the effectiveness of EoL rituals - and mourning rituals in the broad sense.

With respect to our second objective, we identified the forms of EoL ritual acts performed and the themes of EoL communication with the dying. In the Togolese sample, EoL communication and farewell speeches were organized around rituals and were aimed primarily at the passage of the dying person to another existence. Discussions were crystallized around the rituals. The themes that emerge from farewell speeches prove this eloquently (e.g., “... the ancestors are calling me"). Themes were marked by a strong social and collective imagination (e.g., "give me a drink, then call another member of my family to witness this moment"). Current rituals and discourses are integrated into a broad social fabric: spouse, children, friends, close relatives, etc. The higher frequency and richness of the EoL communication could be explained by the "full" time caring by the survivor spouse and family members, which favored the dying person to communicate his/her wills, to provide advices, to talk about his/her imminent death and relationship with ancestors. In the French sample, it is a communication with the dying spouse which confers a beneficial effect on caregiving, although we do not think it should be separated from ritualistic acts. This position is based on the French social model related to the concept of laïcité, which implicitly censures the spontaneous expression of religious acts or beliefs in public healthcare institutions. In these settings, the space of care is reduced to the relationship between health care professionals and the dying, which is not conducive to the realization of ritualistic acts (Launey 2016). Interestingly, we note that these ritualistic acts are, above all, centered on the dying person and performed with the aim of easing the ultimate

\section{3}


passage. Death often releases powerful drive movements (De M'Uzan 1977) and music is "supposed" to soften and soothe the soul of the dying person. These ritualistic practices (videos, music) are widespread in many societies. For example, in Australia, music programs were implemented in many nursing homes to accompany individuals during the phase of dying (Taylor and Box 1999). However, these EoL ritualistic acts identified in the French sample mobilize few networks of solidarity and social ties. The analysis of the content of farewell speeches in the French sample revealed that the content of the last communication was confined to the intimate space of the couple's life (expression and exchange of love) and to the struggles of the dying with their chronic illness. This does not give these rituals a fundamentally social dimension.

Limitations of the present investigation include the small size of the French sample in comparison with the Togolese one. This difference was due to many barriers in recruiting French participants. Our research survey was regarded, unfortunately, as a means of causing participants to re-experience their pain. To overcome this difficulty, the recruitment techniques we used did not permit to recruit bereaved elderly people and to have a large sample size. As a consequence, the average age of participants did not reflect the age life span in the general population ( 85.4 years old for women and 79.5 for men). Another consequence was a limited number of persons reporting the last words of their dying spouse. Losing a spouse who was about 55 years old, suddenly, unexpectedly, as was the case in our sample, could be related to an overmedicalization of healing the "young" dying, which could have reduced the family caregiver's role in assisting the dying. However, the average age of Togolese participants ( 54 years) was near the age life span in the general population (57-58 years). The reader is cautioned to interpret findings accordingly. The second limitation of this manuscript is related to the gap between the two study samples on the time since the death. Particularly, the long periods elapsed since the death in the Togolese sample might have led to anamnestic biases in appreciating items of outcome measures. Other limitations were that the results are based on a cross-sectional design and self-reported data. For example, it is possible that changes in perception of personal growth were attributable to much more time passed since the death. However, results suggested no correlation between bereavement period and postloss growth indicators. In the future, a prospective longitudinal design paired with other measures (e.g., meaning making, continuing bonds with the deceased, etc.) would be of great value.

\section{Conclusion}

In conclusion, the results of the two studies presented and compared in this article provide a modest contribution to the understanding of EoL ritualistic support, EoL informal caregiving, and EoL communication in relation to bereavement reactions. The results revealed that caregiving without ritual support, religious or secular, and therefore without symbolic mediation, predisposed the caregiving spouse to complications of mourning process. Results show that the concept of EoL informal caregiving, ritual practices, as well as communication with the dying could 
potentially be combined into a single integrated model. We suggest a meta-concept that integrates these different aspects and goes beyond the psychosocial aspects of bereavement. It is a form of transcendence of the personal attachment history of each individual that relates to the symbolic experience of life consisting universally of material losses and spiritual gains.

Furthermore, the results suggest new hypotheses. For example, one could explore, from an empirical perspective, how EoL caregiving, communication, and rituals serve as intermediate strategies for finding the meaning of the loss. It might also be interesting to study their involvement in negotiating and rearranging attachment ties with the deceased. Moreover, although these studies have shown that dying is not so deritualized in the French context as one might think, it remains less socialized than it is in the Togolese context. From this point of view, our results show there is a crucial need for the socialization of the EoL phase (Kellehear 2008; Walter 2012). EoL healthcare providers should be able to actively participate in the creation of a space meant for emotional sharing and free exchange of words between the dying person and their relatives.

Acknowledgements The authors thank wholeheartedly all the participants of this study.

Funding The author(s) received no financial support for the research, authorship, and/or publication of this article.

Compliance with Ethical Standards

Conflict of interest Cyrille Kossigan Kokou-Kpolou, Charlemagne S. Moukouta, Livia Sani, SaraEmilie McIntee, Jude Mary Cénat, Atiyihwè Awesso, and Marie-Frédérique Bacqué declare that they have no conflict of interest.

Ethical Approval All procedures performed in studies involving human participants were in accordance with the ethical standards of the institutional and/or national research committee and with the 1964 Helsinki declaration and its later amendments or comparable ethical standards.

Informed Consent Informed consent was obtained from all individual participants included in the study.

\section{References}

American Psychiatric Association

2013 Diagnostic and Statistical Manual of Mental Disorders. 5th Edition. Washington, DC: American Psychiatric Association.

Aries, Phillipe

1974 Western Attitudes Toward Death. London: Johns Hopkins University Press.

1981 The Hour of Our Death. London: Allen Lane.

Bacqué, Marie-Frédérique

2013 Parler du deuil pour éviter de parler de la mort? La société occidentale face aux changements démographiques et culturels du XXIème siècle [Speaking from Bereavement Instead of Speaking from Death? Western Societies in Front of Demographic and Cultural Changes of the 21st Century]. Annales Médico-psychologiques 171:176-181.

\section{3}


Bardin, Laurence

2003 L'analyse de contenu [Content Analysis]. 10eth Edition. Paris: Presses Universitaires de France. Beach, Diane L.

1995 Caregiver Discourse: Perceptions of Illness Related Dialogue. Hospice Journal 10(3):13-25.

Boerner, Kathrin, and Richard Schulz

2009 Caregiving, Bereavement and Complicated Grief. Bereavement Care 28(3):10-13. https:// doi.org/10.1080/02682620903355382.

Currier, Joseph M., Jesse Mallot, Tiffany E. Martinez, Charlotte Sandy, and Robert A. Neimeyer

2013 Bereavement, Religion, and Posttraumatic Growth: A Matched Control Group Investigation. Psychology of Religion and Spirituality 5(2):69-77.

Dassa, Kolou S., Kokou M. Soedje, Kossigan Kokou-Kpolou, and Adama G. Gaba Dovi

2012 Veuvage traditionnel et travail de deuil chez les Ewé du Togo [Traditional Widowhood and Mourning Work at in Ewe Land (Togo)]. Annales africaines de Psychiatrie 1(1\&2):87-97.

Davis, Christopher G., Susan Nolen-Hoeksema, and Judith Larson

1998 Making Sense of Loss and Benefiting from the Experience: Two Construals of Meaning. Journal of Personality and Social Psychology 75:561-574.

Djassoa, Gnansa

1988 Esquisse théorique des pratiques thérapeutiques chez les Nawdeba du Nord Togo. Contribution à l'étude psychologique de la médecine traditionnelle en Afrique Noire [Theoretical model of therapeutic practices among Nawdeba... Contribution to the psychological study of traditional medicine in Black Africa]. Thèse de doctorat de Psychologie, Université de Lomé.

Edmonds, Sarah, and Karen Hooker

1992 Perceived Changes in Life Meaning Following Bereavement. Omega The Journal of Death and Dying 25:307-318

Eisenbruch, Maurice

(1984a) Cross-cultural Aspects of Bereavement I: A Conceptual Framework for Comparative Analysis. Culture, Medicine and Psychiatry 8:283-309.

(1984b) Cross-cultural Aspects of Bereavement. II: Ethnic and Cultural Variations in the Development of Bereavement Practices. Culture, Medicine and Psychiatry 8:315 -347

Elias, Norbert

1985 The Loneliness of the Dying. Oxford: Blackwell.

Gamino, Louis A., Kenneth W. Sewell, and Larry W. Easterling

2000 Scott and White Grief Study-Phase 2: Toward an Adaptive Model of Grief. Death Studies 24(7):633-660

Glaser, Barney G., and Anselm Strauss

1965 Awareness of Dying. Chicago: Aldine.

1968 Time for Dying. Chicago: Aldine.

Gorer, Geoffrey

1965 Death, Grief and Mourning. New York: Doubleday.

Gysels, Marjolein, Christopher Pell, Lianne Straus, and Robert Pool

2011 End of Life Care in Sub-Saharan Africa: A Systematic Review of the Qualitative Literature. BMC Palliative Care 10(1):6.

Hogan, N.S., and L.A. Schmidt

2002 Testing the Grief to Personal Growth Model Using Structural Equation Modeling. Death Studies 26(8):615-634.

K'delant, Pascaline

2010 Le trouble du deuil persistant chez la personne âgée: évaluation et étude des effets de la personnalité. [The persistent bereavement disorder in the elderly: assessment and study of the effects of personality]. University of Nancy: $\mathrm{PhD}$ thesis in psychology, unpublished document.

Keeley, Maureen P., and Julie M. Yingling

2007 Final Conversations: Helping the Living and Dying Talk to Each Other. Ackton: VanderWyk \& Burnham

Kellehear, Allan

2008 Dying as a Social Relationship: A Sociological Review of Debates on the Determination of Death. Social Science \& Medicine 66:1533-1544. 
Kokou-Kpolou, Kossigan, Charlemagne S. Moukouta, Marie-Frédérique Bacqué, Dzodzo E. Kpelly, and Lucy Baugnet

2016 L'accompagnement du mourir et le deuil créateur dans le contexte de la perte du conjoint. Quelques aspects transculturels [Accompaning the Dying and Grief Within the Framework of the Death of a Spouse: Transcultural Perspective]. Etudes sur la Mort 150(2):135-149. https:// doi.org/10.3917/eslm.150.0135.

Kokou-Kpolou, Kossigan, Joël Tremblay, Charlemagne S. Moukouta, and Lucy Baugnet

2017 Unexpected Death, Religious Coping and Conjugal Bereavement Outcomes in Africa (Togo). Mental Health, Religion \& Culture 20(8):766-782. https://doi.org/10.1080/ 13674676.2017.1408578

Kramer, Diane

1997 How Women Relate to Terminally Ill Husbands and Their Subsequent Adjustment to Bereavement. Omega: Journal of Death and Dying 34:93-106.

Kübler-Ross, Elisabeth

1969 On Death and Dying. New York: MacMillan.

1975 Death: The Final Stage of Growth. New Jersey: Prentice Hall.

Launay, Pauline

2016 Du "tabou de la mort" à l'accompagnement de fin de vie. La mise en scène du mourir dans une Unité de Soins Palliatifs française. [From the "taboo of death" to the end-of-life accompaniment. The spatial arrangement of dying process into a French Palliative Care Unit]. Anthropologie \& Santé. https://doi.org/10.4000/anthropologiesante.2094.

Lee, Rebekah, and Megan Vaughan

2008 Death and Dying in the History of Africa Since 1800. Journal of African History 49:341-359. https://doi.org/10.1017/S002185370800395.

Lövgren, Malin, Josefin Sveen, Tommy Nyberg, Alexandra Eilegård Wallin, Holly G. Prigerson, Gunnar Steineck, and Ulrika Kreicbergs

2018 Care at End of Life Influences Grief: A Nationwide Long-Term Follow-Up among Young Adults Who Lost a Brother or Sister to Childhood Cancer. Journal of Palliative Medicine 21:156-162.

McDonald, Deborah D., Deloge Jo-Ann, Joslin Nicole, Weny A. Petow, Judith S. Severson, Roberta

Votino, Michael D. Shea, Jessica M. Drenga, Mary T. Brennan, Andrea B. Moran, and Enrico Del Sigore 2003 Communicating End-of-Life Preferences. Western Journal of Nursing Research 25:652-666.

Metzger, Patricia L., and Matt J. Gray

2008 End-of-Life Communication and Adjustment: Pre-Loss Communication as a Predictor of Bereavement-Related Outcomes. Death Studies 32(4):301-325. https://doi.org/10.1080/ 07481180801928923

Moon, Marilyn

2017 The Unprepared Caregiver. Gerontologist 57(1):26-31. https://doi.org/10.1093/geront/gnw080.

De M'Uzan, Michel

1977 Le travail du trépas [The Work of Death]. Paris: Gallimard.

Mwangi-Powell, Faith N., Richard A. Powell, and Richard Harding

2013 Models of Delivering Palliative and End-of-Life Care in Sub-Saharan Africa: A Narrative Review of the Evidence. Current Opinion in Supportive \& Palliative Care. Current Opinion in Supportive \& Palliative Care 7(2):223-228. https://doi.org/10.1097/SPC.0b013e328360f835.

Pace, J.C., and Tyree S. Mobley

2016 Rituals at End-of-Life. Nursing Clinics 51(3):471-487.

Prigerson, Holly G., Paul K. Maciejewski, III Reynolds, F. Charles, Andrew J. Bierhals, Jason T.

Newsom, Amy Fasiczka, Ellen Frank, Jack Doman, and Mark Miller

1995 Inventory of Complicated Grief: A Scale to Measure Maladaptive Symptoms of Loss. Psychiatry Research 59:65-79.

Rivière, Claude

1982 Deuil et veuvage chez les Evé du Togo [Mourning and Widowhood Among the Evé People of Togo]. Anthropos 77:461-474.

Rosenblatt, Paul C.

2007 Grief: What We Have Learned from Cross Cultural Studies. In Living with Grief: Before and After the Death. K Doka, ed., pp. 123-136. Washington, DC: Hospice Foundation of America.

Sas, Corina, and Alina Coman

2016 Designing Personal Grief Rituals: An Analysis of Symbolic Objects and Actions. Death Studies 40(9):558-569. https://doi.org/10.1080/07481187.2016.1188868.

\section{3}


Schulz, Richard, Randy Hebert, and Kathrin Boerner

2008 Bereavement After Caregiving. Geriatrics 63(1):20-22.

Shear, Katherine M., Naomi Simon, Melanie Wall, Sidney Zisook, Robert Neimeyer, Naihua Duan, I.I.I. Reynolds, Lebowitz Charles, Sung Barry, Ghesquiere Sharon, Gorscak Bonnie Angela, Paula Clayton, Massaya Ito, Satomi Nakajima, Takako Konishi, Nadine Melhem, Kathleen Meert, Miriam Schiff, MaryFrances O'Connor, Michael First, Jitender Sareen, James Bolton, Skritskaya Natalia, Anthony D. Mancini, and Apama Keshaviah

2011 Complicated Grief and Related Bereavement Issues for DSM-5. Depression and Anxiety 28(2):103-117.

Taylor, Andrew, and Margaret Box

1999 Multicultural Palliative Care Guidelines. South Australia: Eastwood.

Tedeschi, Richard G., and Lawrence G. Calhoun

1996 The Posttraumatic Growth Inventory: Measuring the Positive Legacy of Trauma. Journal of Traumatic Stress 9(3):455-471.

Tedeschi, Richard G., and Lawrence G. Calhoun

2004 Posttraumatic Growth: Conceptual Foundations and Empirical Evidence. Psychological lnquiry 15(1):1-18.

Thomas, Louis-Vincent

1985 Rites de mort Pour la paix des vivants [Rites of Death. For the Peace of the Living] Paris: Fayard.

Van Gennep, Arnold 1908/1969 The Rites of Passage. Chicago: University of Chicago Press.

Walter, Tony

2012 Why Different Countries Manage Death Differently: A Comparative Analysis of Modern Urban Societies. British Journal of Sociology 63(1):123-145.

World Health Organization (WHO)

2019 ICD-11 Prolonged Grief Disorder Criteria. WHO (https://icd.who.int/browse11/1-m/en\#/http://id. who.int/icd/entity/1183832314).

Yamaguchi, Takashi, Isseki Maeda, Yutaka Hatano, Masanori Mori, Yasuo Shima, Satoru Tsuneto,

Kizawa Yoshiyuki, Tatsuya Morita, Takuhiro Yamaguchi, Maho Aoyama, and Mitsunori Miyashita

2017 Effects of End-of-Life Discussions on the Mental Health of Bereaved Family Members and Quality of Patient Death and Care. Journal of Pain and Symptom Management. 54(1):17-26. https://doi.org/10.1016/j.jpainsymman.2017.03.008.

Ziegler, Jean

2008 Les vivants et la mort [The Living and The Death]. Paris: Seuil. 